\title{
RISK PERCEPTIONS ON CRUISE SHIPS AMONG YOUNG PEOPLE: CONCEPTS, APPROACHES AND DIRECTIONS
}

\author{
Truc H. Le and Charles Arcodia* \\ Department of Tourism, Sport \& Hotel Management, \\ Griffith Business School, Griffith University, \\ Brisbane-Gold Coast, Australia.
}

\begin{abstract}
Cruising is becoming a more popular form of tourism, leading to the increasingly sophisticated demand and expectations of cruise passengers and the growing number of young cruise passengers. Therefore, it is essential that cruise operators develop a thorough understanding of their customers and determinants influencing the decision-making process. Risk perception plays a key role in affecting purchase intention and retention, and shaping consumer experiences and satisfaction. This paper synthesises the existing knowledge on the role of risk perception in cruising, explores theories underpinning risk perception and its measurements, and identifies key factors influencing risk perception. The paper offers a comprehensive conceptual framework for risk perception on cruise ships, and identifies knowledge gaps that have not yet been explored in the extant cruising literature. This paper contributes to the advancement of risk knowledge in cruise ship behaviour, and allows cruise operators to better understand customer behaviour, especially the youth.
\end{abstract}

Keywords: Risk perception, Cruise ships, Risks and young people

\section{Introduction}

Cruising has been one of the fastest growing sectors of tourism in the last few decades (Pavlic, 2013) achieving increasingly high worldwide passenger (Cruise Lines International Association - CLIA, 2016). Sea cruises have been progressively perceived as a special form of tourism rather than a means of transport (Pavlic, 2013), meaning that the expectations and satisfaction of passengers during cruise trips are becoming increasingly sophisticated. In light of the rapidly growing demand and sophisticated expectations of cruise passengers, it is essential for cruise operators to determine what elements are involved in cruise passengers' decision-making process and how they affect cruising intention and satisfaction. Among them, risk perception is certainly believed to play a vital role in shaping purchase

\footnotetext{
*Email: c.arcodia@griffith.edu.au
} 
intention and mediating consumer decision-making processes (Baker \& Stockton, 2013; Henthorne et al., 2013; Yüksel \& Yüksel, 2007).

However, the cruising literature has portrayed a dearth of research on risk perception on cruise ships (only a few studies including Ahola et al., 2014; Baker \& Stockton, 2013; Bowen et al., 2014; Henthorne et al., 2013; Neri et al., 2008), and even no research on risk perception among potential cruise passengers. These studies, however, only focused on individual types of cruise-related risks (e.g. gastronomic outbreaks, food poisoning, terrorism) without offering a holistic landscape of risk perception in the context of cruise-shipping. Also, the target population of these studies is cruise passengers on the actual ships, which inhibits the possibility of examining potential cruise customers, including the emerging market of Gen Y. Indeed, past research related to cruisers' age shows that there is an assumption that cruise ship experiences were generally for seniors (Hur \& Adler, 2013); however, studies have shown that cruisers are becoming younger than ever before (Baker \& Stockton, 2013; CLIA, 2017; Dowling, 2006). Young people are regarded as Gen Y/Millennials, who were born from 1982 to 1998, as reported in CLIA (2017) Cruise Travel Report. CLIA (2017) finds that younger generation, especially the Millennials, have been embracing cruise travel more than ever before, regarding it as a better vacation type than other types of land-based vacations. Among cruisers, according to CLIA (2017), the most loyal groups are the younger generations, that over two-thirds of the Millennials say that cruising is their favourite vacation. Moreover, $93 \%$ of the Millennials sampled in the report of CLIA (2017) say that they probably or definitely will book a cruise for the next trip. Nevertheless, such statistics would be very questionable if the risk element was mentioned since tourists are in a strong position to practise protective behaviour when noticing risks associated with their vacation (Sönmez \& Graefe, 1998a). Risk perception is therefore able to dismiss or alter the whole decision-making process and induce the decision maker to establish a new decision-making practice. Studying risk perception of young people in the cruise shipping context thus contributes to the knowledge of young people's purchasing behaviour and the level of risk awareness of young people on cruise ships.

Young people may perceive risks differently from other generations. Indeed, Carr (2001) believes, young tourists possess motivations and personality traits that differ from the general population such as sensation-seeking (Pizam et al., 2004), novelty and excitement seeking, and inclinations to engage in physical risks (Lepp \& Gibson, 2003). In addition to the peer effect (Adler \& Adler, 1998), young tourists are more prone to the feeling of "out of space", "out of time", "out of mind" (Pritchard \& Morgan, 2006; Selänniemi, 2003) which can easily distort their risk perceptions and trigger risk-taking 
behaviour (Berdychevsky \& Gibson, 2015). These traits can lead to the distinctiveness between this segment and the general population in risk perception, group composition and attitude towards particular types of tourism products. As a result, there is a need to obtain some further understanding of the behaviours of younger cruise passengers to respond more appropriately to changes in market segments and demand. The study of risk perception among young cruise passengers allows cruise operators to better adapt to their customers' travel intentions and contribute to the implementation of risk management plans on cruise ships that correspond to the concern of this increasingly important market segment. By synthesising the existing knowledge on the role of risk perception in cruising, exploring theories underpinning risk perception and its measurements, and identifying key factors influencing risk perception in the cruising context, this paper offers a conceptual framework of risk perception on cruise ships, and an identification of possible knowledge gaps that have not yet been explored in the existing cruising literature.

\section{The literature}

\subsection{Definition of risk perception}

\subsubsection{Definition of risk}

When it comes to defining risk, there is a large variety of conceptualisations of risk available in the literature. The simplest definition comes from Priest (1990), who defines risk as the potential to lose something of value. Kogan and Wallach (1964) define risk as a "chance" if the focus is on probability and a "danger" if the focus is on the consequence, whereas Reisinger and Mavondo (2006b) refer to risk as "a possibility of danger, harm or loss; and a chance or hazard" (p. 13). From the perspective of consumer research, risk can be defined in terms of the uncertainty of buying a product (Dowling \& Staelin, 1994); the unfavourable consequences of a purchase (Cunningham, 1967; Dowling \& Staelin, 1994); the expectation of loss (Stone \& Winter, 1987); and the amount of loss (Cunningham, 1967). Beside these variations, the most all-encompassing definition comes from Dowling (1986), who defines risk as "the situation where a decision maker has a priori knowledge of both the consequences of alternatives and their probability of occurrence" (р. 194). Sharing the similarity but in a more technical way, the international standard, ISO 31000 (2009) suggests that risk is usually expressed "in terms of a combination of the consequences of an event and the associated likelihood of occurrence". The two elements including the consequences and the likelihood of occurrence conceptualised in Dowling (1986) and ISO 31000 (2009) play an essential part in characterising risks and risk magnitude, either in a cognitive decision-making process or in an organisational scale. These two elements have been incorporated in the risk acceptance criteria, which is usually represented in a matrix that is used as a basis for decisions about acceptable risk (see Figure 1). This study adapts the risk definition offered 
by Dowling (1986) and ISO 31000 (2009) to examine risks on cruise ships and employs the risk acceptance matrix as a guide for further risk perception measurements in the latter study.

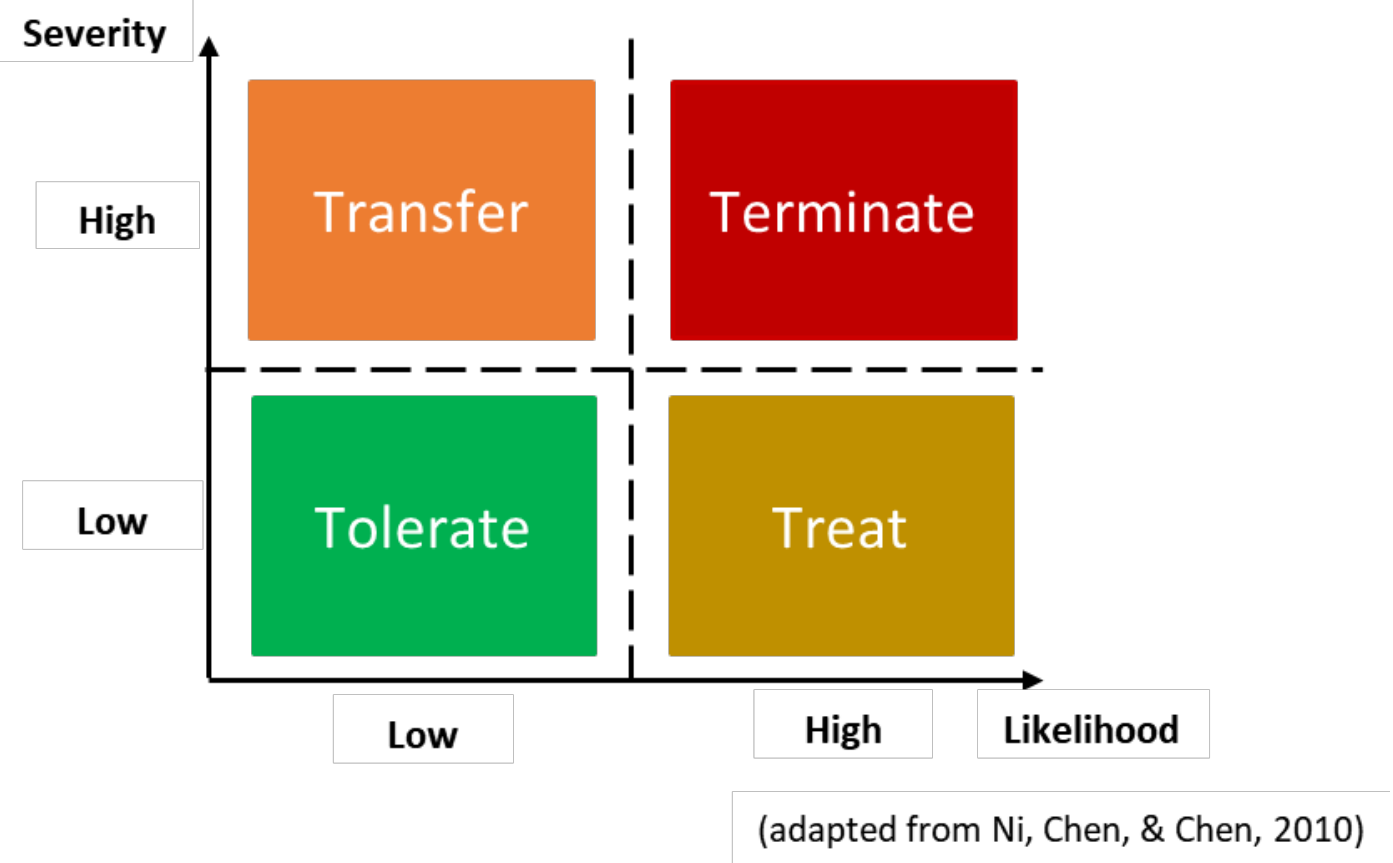

Figure 1. Risk Acceptance Matrix.

\subsubsection{Risks associated with cruise ships}

A number of risks happening on-board have been identified in past cruise studies. For example, infection outbreaks represent a significant public health issue on cruise ships (Kak, 2007) considering the accelerated rate of occurrence in recent years (Bell et al., 2014). Also, the presence of bars and nightclubs, in addition to the willingness of youth to express themselves and follow their peers (Crotts, 1996), makes cruise ships "hot spots" of increased sexual behaviour, which may lead to the likelihood of acquiring sexually transmissible infections. Motion sickness, on the other hand, is one of the main reasons why travelling by sea can be a bad experience, and is usually the most common illness happening on-board (Bledsoe et al., 2007). Since the number of cruise accidents resulting in severe damage and lives lost are substantial every year, cruise accidents are apparently one of the major concern on cruise ships (Ventikos, 2013). Finally, terrorism, piracy, and crime are regarded as major security threats that cause serious violence to a large number of cruise passengers (Bowen et al., 2014; Panko et al., 2009).

\subsubsection{Definition of risk perception}

Whereas risk analysts implement risk assessment to evaluate risks, the majority of people use their intuitive risk judgment to evaluate them, which is typically referred to as risk perception (Slovic et al., 
1982). A number of studies have been conducted to examine risk perception, in which researchers pay attention to determine how people judge, characterise and evaluate hazardous activities (Slovic et al., 1982). A two-dimensional structure of risk perception was proposed by Bauer (1960) including uncertainty and adverse consequences. Indeed, uncertainty is defined in terms of probabilistic beliefs, whereas adverse consequences refers to importance of loss when attempting to achieve a set of buying goals (Dowling, 1986). In addition to the two-dimensional structure, researchers have suggested that perception of risk is related to various types of loss such as social, physical, financial, psychological, time, etc. (Dowling, 1986). In sum, risk perception can be defined as a two-dimension (probability and importance of loss) (Bauer, 1960; Dowling, 1986) and multi-faceted (social, physical, financial, psychological, time loss, etc.) construct. However, since little consensus regarding this construct's precision and how to measure it has been achieved, thus, risk perception is still regarded as a 'fuzzy' concept (Dowling, 1986).

On the other hand, Mitchell et al. (1999) and Haddock (1993) acknowledge risk is perceived in at least two levels. Specifically, product-category risk (perceived risk) reflects an individual's perception of the risk involved in purchasing any product, whereas product-specific risk (absolute risk) is the actual risk associated with the consumption of that product. This acknowledgement imply that there should be a clear boundary between examining risk perception and perception of associated risks (Haddock, 1993; Mitchell et al., 1999). Henthorne et al. (2013) agree with these arguments as they state that "the concept of perceived risk defined risk from the viewpoint of the consumer" (p. 70), thus, "the perception of risk may or may not match with the actual risks involved" (p. 83). However, Mitchell et al. (1999) assert that the product-specific risks (absolute risks) are most real to consumers and most relevant to marketers comparing to product-category risks (perceived risks). Therefore, it is important that the examination of risk perception, on one hand, focuses on the consumer's perspective (productcategory risk), on the other hand, highlights the importance of examining perception of productspecific risks (keeping the risks real) so that the significance of these risks in is not overlooked in reality.

\subsubsection{Risk perception on cruise ships}

A limited number of studies investigate risk perception and its impact on cruiser decision-making. Henthorne et al. (2013) for example, examine risk and safety perception of cruise travel in the context of cruise excursions, and examine how these perceptions influence shopping behaviour in port destinations. The significant impact of risk and safety perception on the travellers' intention to return to a specific destination is strongly emphasised. Henthorne et al. (2013) argue cruise tourists are usually constrained to limited onshore activities such as sightseeing and shopping due to time 
restrictions. A noteworthy difference was also highlighted among first time and repeat visitors in which the first timers express higher levels of discomfort with the surroundings than do the repeaters, who would experience less fear and anxiety and feel less insecurity (Henthorne et al., 2013). Nevertheless, this study delimits its scope by not examining risk perception concerning on-board cruise activities, even though several on-board activities are the root of risks associated with cruise ships. Despite having a different research aim from Henthorne et al.'s study, Hung and Petrick's (2010) research on constraints to cruising also exposed the distinction between cruisers (repeat passengers) and non-cruisers (first time passengers) in cruising constraints, indicating risk perception may also be influenced by past travel experiences.

Other studies narrow their scope by examining cruiser perception of specific risks associated with cruise ships. In particular, Baker and Stockton (2013) examine passengers' perception of food safety and their demographics on an Eastern Caribbean cruise. Even though the results show that cruise passengers were not overly concerned about the cruise ship's food safety practices because they are knowledgeable about food safety and more aware of it due to the widespread media reporting, there are significant differences in perception among different level of cruise experience. The study found that second and third time cruise takers tend to consult with their healthcare providers before starting the cruise, whereas first time cruise takers are more likely to take personal precautions to prevent illness and disease while on cruise ships. Therefore, it is implied that past travel experiences are likely to have significant impact on the health perception of cruise passengers (Baker and Stockton, 2013). This conclusion aligns with Bowen et al.'s (2014) finding whose study investigates tourist perception of potential terrorist threat to cruise shipping. Bowen et al. (2014) believe risk perception is individualistic and different from person to person, thus it is essential to take into account individual demographics and past travel experiences when discussing risk perception. However, Sönmez and Graefe (1998b) raise a controversial issue when maintaining that neither demographic characteristics nor past experiences directly influence risk perception and decision-making process. This may result from the risk context examined in this study was terrorism risk/political instability. More specifically, regardless of either any demographic characteristics or past experiences, decisions of travelling abroad, the amount of information gathered about the destination, and the concern of safety in lights of terrorism threat were strongly predicted by level of risk perception, income and attitude toward international tourism (Sönmez and Graefe, 1998b).

Also, Ahola et al. (2014) examine passengers' perception of safety on cruise ships and suggest that human perceptions of the surrounding environment significantly affect behaviour. The authors 
highlight passengers' risk perception plays an important role in the effectiveness of a cruise's risk management plan. Ahola et al. (2014) argue "when people lack accurate perceptions about safety, their behaviour places the lives of all the passengers at risk because of the fact that they have not properly read the safety instructions" (p. 223). After all, the aim of studying risk perception of cruise passengers is to assume a proactive approach for risk management on cruise ships. Table 1 presents the existing studies examining risk perception in the cruising context. This includes studies examining general risk perception on cruise ships and those focusing on specific risks associated with cruise ships. This table assesses these studies in terms of research objectives, type of risk, type of methodology used, method of data collection, the sample, method of data analysis, and key findings. The table suggests that the existing literature has touched only the smallest tip of the iceberg where perception has been examined among a single risk, which lacks a holistic view of risk perception on cruise ships where there are many threats perceived and faced by passengers. 
Table 1. Studies examining risk perception on cruise ships.

\begin{tabular}{|c|c|c|c|c|c|c|c|}
\hline Authors & Research Objectives & Type of Risk & $\begin{array}{c}\text { Type of } \\
\text { Methodology }\end{array}$ & $\begin{array}{l}\text { Method of Data } \\
\text { Collection }\end{array}$ & Sample & $\begin{array}{l}\text { Method of Data } \\
\text { Analysis }\end{array}$ & Key Findings \\
\hline $\begin{array}{c}\text { Ahola et al. } \\
\text { (2014) }\end{array}$ & $\begin{array}{l}\text { Discuss how people } \\
\text { perceive safety } \\
\text { within the context } \\
\text { of passenger ships. } \\
\text { Highlight the } \\
\text { importance of } \\
\text { human safety } \\
\text { perception within } \\
\text { the context of } \\
\text { passenger ship } \\
\text { safety design. }\end{array}$ & Ship safety & $\begin{array}{l}\text { Qualitative } \\
\text { approach - two } \\
\text { Field studies }\end{array}$ & $\begin{array}{l}\text { Interviews elicit a } \\
\text { broad range of } \\
\text { issues related to } \\
\text { passenger safety } \\
\text { perceptions. } \\
\text { Self-documenting } \\
\text { approach illustrates } \\
\text { the participants' } \\
\text { optional } \\
\text { observation route } \\
\text { with empty lines for } \\
\text { the critical features } \\
\text { of the environment. }\end{array}$ & $\begin{array}{l}1^{\text {st }} \text { field study: } 10 \text { Aalto } \\
\text { university master's } \\
\text { level students (all first } \\
\text { time cruisers) } \\
\text { travelled on a cruise } \\
\text { ship from Portugal to } \\
\text { Brazil in November } \\
2011 . \\
2^{\text {nd }} \text { field study: } 7 \\
\text { passengers in a one- } \\
\text { week Mediterranean } \\
\text { cruise between } \\
\text { August and } \\
\text { September of } 2012 .\end{array}$ & Content analysis & $\begin{array}{l}\text { Passengers perceive safety via } \\
\text { the architecture of the } \\
\text { passenger ship, the life- } \\
\text { saving appliances, } \\
\text { communication, emotions } \\
\text { and other people. } \\
\text { Human perceptions and } \\
\text { reactions to the } \\
\text { surrounding environment } \\
\text { significantly affect } \\
\text { behaviour and should be } \\
\text { studied in parallel with } \\
\text { technical progress. }\end{array}$ \\
\hline $\begin{array}{l}\text { Baker and } \\
\text { Stockton } \\
(2013)\end{array}$ & $\begin{array}{l}\text { Determine cruise } \\
\text { passengers } \\
\text { demographics and } \\
\text { their health } \\
\text { perceptions while } \\
\text { cruising the Eastern } \\
\text { Caribbean. }\end{array}$ & Food safety & $\begin{array}{l}\text { Quantitative } \\
\text { approach - Survey } \\
\text { research method }\end{array}$ & $\begin{array}{l}\text { Self-administered } \\
\text { questionnaire } \\
\text { consists of } 5 \\
\text { checklist questions } \\
\text { on demographic } \\
\text { characteristics and } \\
13 \text { statements } \\
\text { relating to food } \\
\text { safety perceptions, } \\
\text { health perceptions } \\
\text { and information } \\
\text { sources. }\end{array}$ & $\begin{array}{l}125 \text { on-board passengers } \\
\text { from two cruise ships } \\
\text { on seven-day cruises } \\
\text { of the Eastern } \\
\text { Caribbean Islands in } \\
\text { March, } 2012 \text {. }\end{array}$ & $\begin{array}{l}\text { SPSS } 18.0 \text { was used } \\
\text { for frequency, } \\
\text { percentage, mean, } \\
\text { standard deviation } \\
\text { and one-way } \\
\text { ANOVA. } \\
\text { One-way ANOVA was } \\
\text { used to test for } \\
\text { preference } \\
\text { differences among } \\
\text { four means for first } \\
\text { time cruisers, } \\
\text { second time } \\
\text { cruisers, third time } \\
\text { cruisers and more } \\
\text { than } 3 \text { time } \\
\text { cruisers. }\end{array}$ & $\begin{array}{l}\text { A high percentage of cruise } \\
\text { ship passengers were } \\
\text { younger, fairly educated } \\
\text { with annual incomes } \\
\text { exceeding } \$ 50,000 \text {. } \\
\text { Consumers were } \\
\text { knowledgeable about food } \\
\text { safety, more aware of food } \\
\text { safety issues, and not overly } \\
\text { concern about their cruise } \\
\text { ship food safety. } \\
\text { There are significant } \\
\text { differences between means } \\
\text { among the groups with } \\
\text { number of cruise traveller } \\
\text { experience. }\end{array}$ \\
\hline
\end{tabular}


Table 1. Continued.

\begin{tabular}{|c|c|c|c|c|c|c|c|}
\hline Authors & Research Objectives & Type of Risk & $\begin{array}{c}\text { Type of } \\
\text { Methodology }\end{array}$ & $\begin{array}{l}\text { Method of Data } \\
\text { Collection }\end{array}$ & Sample & $\begin{array}{c}\text { Method of Data } \\
\text { Analysis }\end{array}$ & Key Findings \\
\hline $\begin{array}{l}\text { Bowen et al. } \\
\text { (2014) }\end{array}$ & $\begin{array}{l}\text { Analyse tourist } \\
\text { perception of } \\
\text { perceived terrorist } \\
\text { threats given that } \\
\text { many ships are } \\
\text { American owned. }\end{array}$ & Terrorism & $\begin{array}{l}\text { Mixed method } \\
\text { approach }\end{array}$ & $\begin{array}{l}\text { A questionnaire } \\
\text { adopting face-to- } \\
\text { face strategy was } \\
\text { used with open- } \\
\text { ended and closed } \\
\text { questions. } \\
\text { Structured interview } \\
\text { with a director from } \\
\text { a leading cruise ship } \\
\text { operator was used } \\
\text { to further explore } \\
\text { the issues identified } \\
\text { in terms of cruise } \\
\text { line security. }\end{array}$ & $\begin{array}{l}\text { Questionnaire: } 144 \\
\text { visitors at the } \\
\text { London Olympia } \\
\text { Exhibition Centre, } \\
\text { the venue for } \\
\text { CRUISE, a dedicated } \\
\text { 2-day cruise } \\
\text { shipping exhibition } \\
\text { sponsored by the } \\
\text { UK national } \\
\text { newspaper The } \\
\text { Daily Telegraph, on } \\
\text { the } 26 \text { March 2011. } \\
\text { Structured interview: a } \\
\text { director from a } \\
\text { leading cruise ship } \\
\text { operator } \\
\text { (anonymous). }\end{array}$ & $\begin{array}{l}\text { Quantitative data: SPSS } \\
18.0 \text { for measures of } \\
\text { central tendency and } \\
\text { chi-square analysis. } \\
\text { Qualitative data: } \\
\text { content analysis. }\end{array}$ & $\begin{array}{l}44 \% \text { of respondents } \\
\text { questioned perceived the } \\
\text { possibility of a terrorist } \\
\text { attack on a cruise ship to be } \\
\text { likely despite the fact that } \\
\text { safety and security is seen } \\
\text { by the industry as a } \\
\text { 'hallmark' of cruising. } \\
\text { Differences in attitude among } \\
\text { potential passengers } \\
\text { revealed a high level of } \\
\text { confidence in the cruise } \\
\text { ship companies. This finding } \\
\text { is particularly marked } \\
\text { among more experienced } \\
\text { cruise ship passengers. }\end{array}$ \\
\hline $\begin{array}{l}\text { Henthorne et } \\
\text { al. (2013) }\end{array}$ & $\begin{array}{l}\text { Examines the issue of } \\
\text { perceived risk and } \\
\text { safety and what } \\
\text { impact these } \\
\text { perceptions have } \\
\text { on shopping } \\
\text { behaviour. }\end{array}$ & Security & $\begin{array}{c}\text { Quantitative } \\
\text { approach with } 3 \\
\text { hypotheses }\end{array}$ & Questionnaire & $\begin{array}{l}258 \text { passengers that } \\
\text { had disembarked } \\
\text { from cruise ships for } \\
\text { a walking visit into } \\
\text { Ocho Rios port of } \\
\text { call, Jamaica. }\end{array}$ & $\begin{array}{l}\text { Univariate analysis was } \\
\text { used to compare } \\
\text { visitors and non- } \\
\text { visitors. } \\
\text { ANOVA was used to } \\
\text { determine the } \\
\text { differences in future } \\
\text { visit intention } \\
\text { between the groups. } \\
\text { AMOS path analysis } \\
\text { tests whether } \\
\text { expectations mediate } \\
\text { the relationship } \\
\text { between the } \\
\text { shopping experience } \\
\text { and the likelihood of } \\
\text { returning to Jamaica. }\end{array}$ & $\begin{array}{l}\text { Those visitors who travelled } \\
\text { with others spent more } \\
\text { time shopping and } \\
\text { purchased more. } \\
\text { First time visitors express } \\
\text { higher levels of discomfort } \\
\text { with their surroundings } \\
\text { than did repeat visitors, } \\
\text { thus inhibiting purchase } \\
\text { behaviour. } \\
\text { Levels of perceived risk and } \\
\text { security did have an impact } \\
\text { on a traveller's intention to } \\
\text { return to Jamaica. }\end{array}$ \\
\hline
\end{tabular}


Table 1. Continued.

\begin{tabular}{|c|c|c|c|c|c|c|c|}
\hline Authors & Research Objectives & Type of Risk & $\begin{array}{c}\text { Type of } \\
\text { Methodology }\end{array}$ & $\begin{array}{l}\text { Method of Data } \\
\text { Collection }\end{array}$ & Sample & $\begin{array}{c}\text { Method of Data } \\
\text { Analysis }\end{array}$ & Key Findings \\
\hline $\begin{array}{c}\text { Neri et al. } \\
\text { (2008) }\end{array}$ & $\begin{array}{l}\text { Understand the } \\
\text { behaviour and } \\
\text { practices of people } \\
\text { who have become } \\
\text { ill with Norovirus } \\
\text { illness compared to } \\
\text { those who } \\
\text { remained well } \\
\text { during an outbreak. }\end{array}$ & $\begin{array}{l}\text { Outbreaks of } \\
\text { gastrointestin } \\
\text { al illness }\end{array}$ & $\begin{array}{l}\text { Quantitative } \\
\text { approach }\end{array}$ & $\begin{array}{l}\text { A paper-based } \\
\text { questionnaire } \\
\text { administered to } \\
\text { passengers prior to } \\
\text { disembarkation. }\end{array}$ & $\begin{array}{l}\text { 1,323 passengers from } \\
\text { three cruise ship } \\
\text { outbreaks caused } \\
\text { by Norovirus } \\
\text { between January } \\
\text { and April } 2006 .\end{array}$ & $\begin{array}{l}\text { SAS v9.1.3 was used for } \\
\text { odds ratios (OR) in } \\
\text { case-control studies, } \\
\text { risk ratios (RR) in } \\
\text { cohort studies, and } \\
\text { the Mann - Whitney } \\
\text { - Wilcoxon (MWW) } \\
\text { rank sum test for } \\
\text { non-parametrically } \\
\text { distributed values. }\end{array}$ & $\begin{array}{l}\text { Most cases delayed or did not } \\
\text { report their illness to the } \\
\text { ship's infirmary because } \\
\text { they did not believe it was } \\
\text { serious. } \\
\text { Cases were less likely to } \\
\text { believe that hand sanitizer } \\
\text { and isolation are effective } \\
\text { means of preventing } \\
\text { disease spread. } \\
\text { Cases were less likely to } \\
\text { believe that hand sanitizer } \\
\text { was available for public use } \\
\text { prior to/after knowing } \\
\text { about an outbreak. }\end{array}$ \\
\hline
\end{tabular}




\subsection{The role of risk perception in travel behaviour}

In the field of consumer behaviour, previous research offers robust arguments that risk perception directly affects purchase intentions (Mitchell et al., 1999; Henthorne et al., 2013; Maser \& Weiermair, 1998; Sönmez \& Graefe, 1998b; Yüksel \& Yüksel, 2007). Moreover, understanding purchase intentions and consumer behaviour in general first requires an understanding of the causes influencing the behaviour (Ahola et al., 2014); the way in which perception of the environment and its attributes guide consumers' response which in turn guides consumer behaviour (Crilly et al., 2004). Chaudhuri (2000) found that customer decision-making is fully mediated by the risks perceived during the information search. This supports Bauer's (1960) claim that consumer decision-making involves assessment of risk consequences if they view the buying action with some level of uncertainty. The research of Reisinger and Mavondo (2006b) and Yüksel and Yüksel (2007) on the effects of risk perception on tourist satisfaction and loyalty intentions further portrays that risk perception creates emotions that cause anxiety and fear the purchasing intentions, which place substantial constraints on tourist travel and encourage more cautious behaviours.

Despite the adverse effect that risk perception has on travel behaviour, risk perception can serve as a facilitated factor that stimulates risk-taking behaviour (Dowling, 1986). Indeed, when a productrelated risk is perceived as not important because of predominant effects of boredom, curiosity, or sensational-seeking, that risk may be ignored or rejected (Dowling, 1986). In other words, risk-adverse individuals may always attempt to reduce the perceived risk, whereas risk-taking individuals tend to ignore the risk consequences and increase risk (this usually happens in adventure travel such as skydiving, windsurfing, bungee jumping, etc.).

More importantly, Roehl and Fesenmaier (1992) emphasise that understanding tourists' risk perception has substantial impacts on successful marketing strategies for travel-related products. In their study, the effect of perception of travel-related risks is investigated by examining the three basic dimensions of perceived risk: physical-equipment risk including risk dimension associated with the physical well-being and equipment risks; vacation risk including dimension associated with vacations, involving financial, psychological, satisfaction, and time risks; and destination risk including dimensions associated with the most recently visited destination, also involving financial, psychological, satisfaction, and time risk components (Roehl \& Fesenmaier, 1992). This study suggests that the relationship between risk perception and consumer behaviour, especially in the tourism context, appears to be situation-specific, meaning that the perception of risk in different settings is heterogeneous (Roehl \& Fesenmaier, 1992). Applying this typology to the cruising context, physical- 
equipment risk and destination risk are most appropriate for examining risk perception on cruise vacations, which include the perceived risks exposed to cruise passengers either on-board or when visiting particular destinations at ports. However, giving that this study only focuses on examining risk perception in the cruise ship context (on the ship, not the excursions), physical-equipment risk is the most appropriate type to discuss.

\subsection{Theories underpinning risk perception}

Understanding risk perception firstly requires an understanding of theoretical roots shaping risk perception. Kozak et al. (2007) argue that due to the tourism characteristics of high uncertainty and high financial and personal risks, risk perception and safety concerns have become a central issue in the complex travel decision-making process. Risk perception serves as a critical foundation for information search to reduce the perceived risks, thus, plays a vital role in influencing travel decisionmaking evaluation (Maser \& Weiermair, 1998). However, debates have arisen questioning whether the understanding of the traditional decision-making process is sufficient to understand risk perception in risk-related scenarios, or there are any other theories offering an in-depth understanding of how risk perception actually affects travel decisions.

\subsubsection{Discrepancies in understanding risk perception in the traditional decision-making model}

When it comes to the role of risk in consumer decision-making process, Sönmez and Graefe (1998a) have raised a controversial issue about whether risk has potential to alter the decision-making process, and whether the traditional consumer decision-making framework is a solid theoretical foundation for understanding risk perception and behaviour of tourists. Indeed, traditional consumer decision-making research has long been utilised to examine tourist decision-making, emphasising the role of choice sets and decision modelling. However, Sönmez and Graefe (1998a) argue this framework might be insufficient when applying in situations involving risks. They suggest the insufficiency is derived from the fact that the risk has potential to substitute the conventional decision process and cause travellers to change their plans. Sönmez and Graefe (1998a) assert "regardless of whether real or perceived, the presence of risk has the potential to change the nature of travel decisions" (Sönmez \& Graefe, 1998a, p. 173).

\subsubsection{Information Integration Theory and Protection Motivation Theory}

To overcome this limit, Sönmez and Graefe (1998a) propose Anderson's $(1981,1982)$ Information Integration Theory (IIT) and Roger's $(1975,1983)$ Protection Motivation Theory (PMT) to better understand how risks impact on travel decisions. Information Integration Theory (Anderson, 1981, 
1982) advises that psychological and value judgements are shaped by individuals according to complex decision-making steps. Indeed, whereas psychological judgements are the subjective perception of physical reality, value judgements refer to how individuals rank their alternatives according to the attributes. These judgements may change if additional alternatives are added to the evaluation, new information which may change the consideration is learned, or travellers' perception of an alternative is changed due to the new information, prior to final choice.

Protection Motivation Theory (Rogers, 1975, 1983) concentrates on the three cognitive processes that individuals experience in a risky decision including evaluating threat intensity, considering the likelihood of occurrence, and estimating capability of coping response. This theory suggests that the likelihood of engaging in protective behaviour is high when an individual perceives high magnitude and high probability of the risk, and the high availability of effective means (including external actions and the individual's own capability) to control the consequences (Sönmez \& Graefe, 1998a). Together, IIT and PMT pose that future travel decisions are seen as protective behaviour or risk avoidance affected by risk perception and the past experiences individuals have on that type of travel. In other words, tourists are in a strong position to practise protective behaviour when noticing risks associated with their vacation using their subjective perception and past experiences (Sönmez \& Graefe, 1998a). This conclusion contributes significantly to the knowledge of factors influencing risk perception and adds weight to the argument that a traditional decision-making framework should be altered by the involvement of risk.

As a result, while the traditional decision-making model proves its sufficiency in analysing the decisionmaking process of the general purchasing behaviour, its applicability is questionable in risk-related scenarios. Information Integration Theory and Protection Motivation Theory pose significant possible directions to compensate this discrepancy. The subjective perception of physical reality in conjunction with the cognitive process of evaluating the threats, and the evaluation of possible alternative routes are proposed by these two theories that explains how decision makers generate sufficient protective behaviour in the situation involving risks. This type of behaviour may consist of reducing or avoiding the involvement with the service or activity, consequently altering the whole decision-making process and induce the decision maker to establish a new decision-making practice.

\subsection{Measurement of risk perception}

As risk perception is situation-specific (Roehl \& Fesenmaier, 1992) and involves a number of cognitive judgments (Anderson, 1981, 1982; Rogers, 1975, 1983), it is somewhat regarded as a 'fuzzy' concept 
(Dowling, 1986). Therefore, a consensus measurement framework to determine risk perception is challenging to generate. Also, due to the large variety of conceptualisations of risk available in the literature, several types of risk perception measurement have been proposed resulting in different levels of relevance applying to risk perception examination. More importantly, the relevance of risk perception measurement level may determine the feasibility of the study and may suggest possible research approaches to be conducted.

\subsubsection{The psychometric paradigm}

One broad strategy for studying risk perception discussed in Slovic et al.'s (1982) and Slovic's (1987) study is developing a risk taxonomy that classifies risks into categories to understand and predict people's response. According to Slovic (1987), the taxonomy seeks to explain how adversely people perceive particular risks and identify the similarities and differences in risk perception among individuals and groups. The psychometric paradigm has been utilised to fulfil this aim. This paradigm refers to the use of "psycho-physical scaling and multivariate analysis techniques to produce quantitative representations or cognitive maps of risk attitudes and perceptions" (Slovic, 1987, p. 281). In the psychometric paradigm, people are asked to make quantitative judgments about the perceived riskiness of various risks and the desired level of regulation of each (see Figure 2) (Slovic et al., 1982). This strategy has shown that risk perception is quantifiable and predictable and it serves as an effective technique for identifying similarities and differences in risk perception among individuals and groups. 


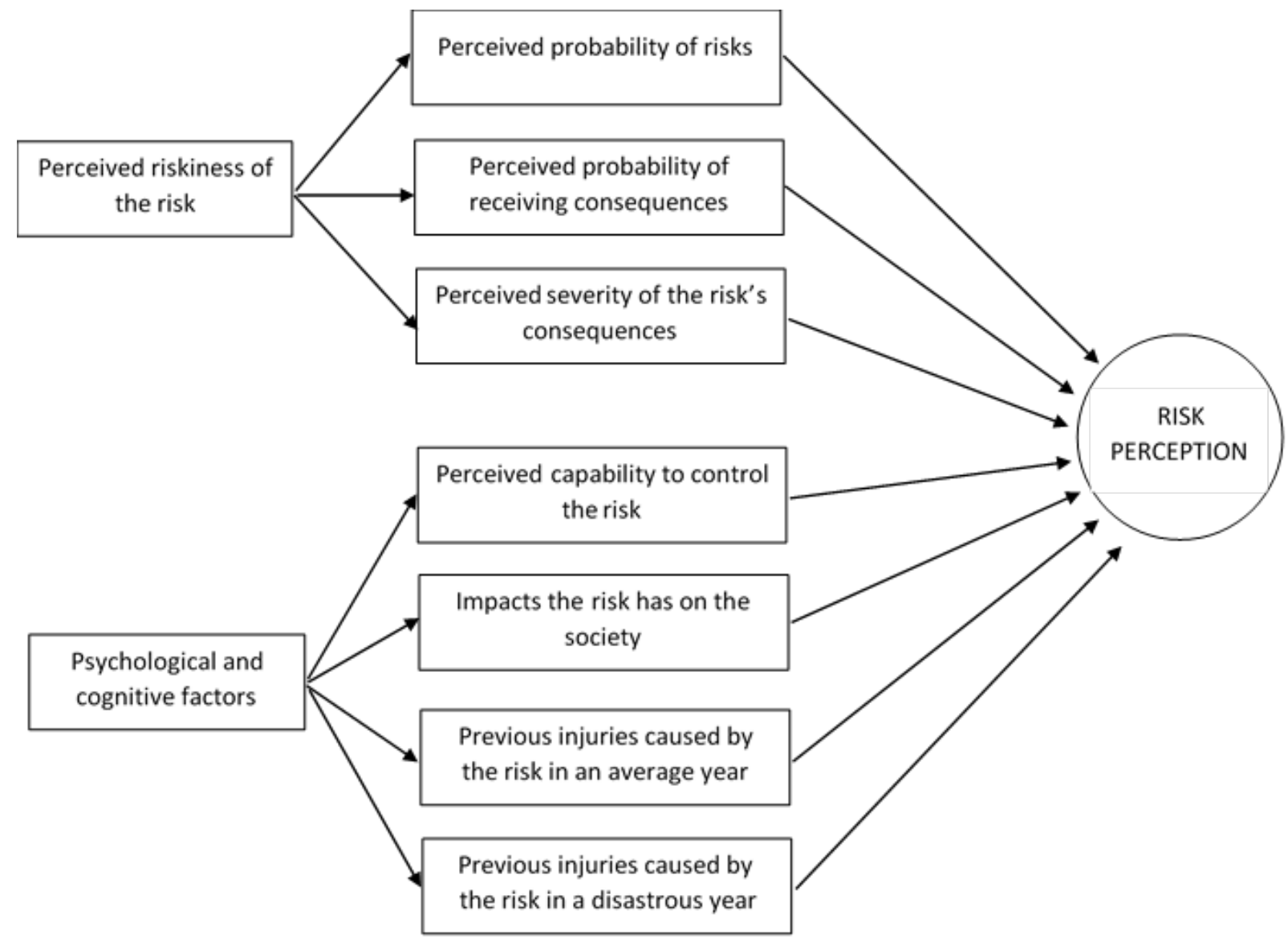

(adapted from Slovic, 1987)

Figure 2. The psychometric paradigm.

\subsubsection{Relationship between uncertainty and adverse consequences}

According to Dowling (1986), risk perception has been conceptualised and operationalized at different levels of abstraction; however, low level measures appear to be a powerful predictor of consumer behaviour. In particular, measures with low level of abstraction focus on risk perception of a single product by examining the relationship between the two components of risk, namely, uncertainty (probability of loss) and adverse consequences (importance of loss) (Cunningham, 1967) (see Table 2). Dowling (1986) regards measurement of perceived risk at a low level of abstraction is a solid predictor of consumer behaviour because there are fewer variables interfering between risks and buying behaviour. This model has been used in Mitchell and Vassos' (1997) and Mitchell et al.'s (1999) study to investigate perceived risk and risk reduction in holiday purchases. However, these types of measures may not offer generalizability, especially in the tourism context, because the relationship between risk and buying behaviour is situation-specific, thus different settings may involve different types of loss. From a conceptual standpoint, the equations are also criticised that it is reasonable to assume one component equalled zero (either uncertainty or adverse consequences) will result in zero 
in perceived risk whereas either uncertainty or adverse consequences might affect perceive risk on its own (Schmidt \& Wilson, 1975).

Table 2. Low level measure of risk perception.

\begin{tabular}{|c|c|}
\hline \multicolumn{2}{|c|}{ THE RELATIONSHIP BETWEEN UNCERTAINTY AND ADVERSE CONSEQUENCES } \\
\hline $\begin{array}{c}\text { MULTIPLICATIVE } \\
\text { VERSION }\end{array}$ & $\begin{array}{c}\text { Perceived risk = Uncertainty } \times \text { Adverse Consequences } \\
\text { Overall perceived risk }=\sum_{i=1}^{n} \text { Uncertainty } \times \text { Adverse Consequences } \\
\mathrm{n}=\text { the number of types of loss } \mathrm{i}\end{array}$ \\
\hline $\begin{array}{c}\text { ADDITIVE } \\
\text { VERSION }\end{array}$ & $\begin{array}{r}\text { Perceived risk }=\text { Uncertainty }+ \text { Adverse Consequences } \\
\text { Overall perceived risk }=\sum_{i=1}^{n} \text { Uncertainty }+ \text { Adverse Consequences } \\
\mathrm{n}=\text { the number of types of loss } \mathrm{i}\end{array}$ \\
\hline
\end{tabular}

(adapted from Cunningham, 1967)

\subsubsection{Other types of measures}

Other types of measures have been proposed in the literature to determine risk perception among particular products. The most common type is described as "a unidimensional measure" which seeks to ask people to rank the riskiness and probability of a hazard, an activity or a product through a range of scale from 'not risky' and/or 'least likely' to 'extremely risky' and/or 'most likely' (Dowling, 1986; Henthorne et al, 2013; Kozak et al., 2007; Reisinger \& Crotts, 2009; Reisinger \& Mavondo, 2006a, 2006b; Sharifpour et al., 2013; Sönmez \& Graefe, 1998a, 1998b). Other types of numeric measures arise from the possibility that individuals perceive risk in comparison with others rather than their absolute manner, namely, the risk difference and the relative risk (Krosnick, 2001).

The review of different types of risk perception measurements suggests a number of approaches to examine risk perception, not only in the tourism but also in other research contexts. Despite being regarded as fuzzy and somewhat unpredictable (Dowling, 1986; Roehl \& Fesenmaier, 1992), these types of measurement have added weight to the indication that risk perception is not an immeasurable concept. However, the choice of measurement is still contextual, situation-specific, and dependent on types of research and research objectives. The measurement of risk perception in this study is adapted from Cunningham's (1967) two-component risk uncertainty and adverse consequences model. This measurement has been used by many perceived risk researchers since 1967 (e.g. Guseman, 1981; Hoover et al., 1978; Mitchell \& Greatorex, 1993; Mitchell \& Vassos, 1997; Peter \& Ryan, 1976; Verhage et al., 1992). However the additive model is more favourable than the multiplicative version due to the disadvantaged nature of multiplication (zero overall perceived risk 
exists if one component equals zero). The review of existing studies in risk perception on cruise ships and the illustration of perceived risk measurement offer propositions as follows:

P1: Perception of risks can be captured/assessed by the additive effect of two dimensions, namely, perceived uncertainty and perceived adverse consequences.

P1a: Perception of infection outbreaks can be captured/assessed by the additive effect of two dimensions, namely, perceived uncertainty and perceived adverse consequences.

P1b: Perception of sexually transmissible infections can be captured/assessed by the additive effect of two dimensions, namely, perceived uncertainty and perceived adverse consequences.

P1c: Perception of motion sickness can be captured/assessed by the additive effect of two dimensions, namely, perceived uncertainty and perceived adverse consequences.

P1d: Perception of cruise accidents can be captured/assessed by the additive effect of two dimensions, namely, perceived uncertainty and perceived adverse consequences.

P1e: Perception of terrorism, piracy and crime can be captured/assessed by the additive effect of two dimensions, namely, perceived uncertainty and perceived adverse consequences.

\subsection{Factors influencing risk perception}

It is suggested that risk perception is an individualised concept because what is perceived as a high risk to one person may be perceived as a low risk to another (Reisinger \& Mavondo, 2006a). Previous tourism literature has identified numerous factors that result in such differences. Such differences may result from differences in national culture and cultural dimensions in particular, differences in gender, age, types of personality, types of motivation to travel, and differences in past travel experiences between groups of individuals.

\subsubsection{National culture}

National culture is considered as a key factor that explains the differences in tourists' risk perception (Kozak et al., 2007; Mitchell \& Vassos, 1997; Pizam \& Reichel, 1996; Pizam \& Sussmann, 1995; Reisinger \& Crotts, 2009; Reisinger \& Mavondo, 2005; Reisinger \& Mavondo, 2006a; Seddighi et al., 2001). Most of the researchers agree that the level of perceived risk is varied according to the tourist's national culture (Kozak et al., 2007; Richardson \& Crompton, 1988; Seddighi et al., 2001). By evaluating the impact of Hofstede's (1980) cultural dimensions, Hofstede and Bond's (1988) Long/Short-Term Orientation, and Hall's (1976) High/Low Context Cultural Orientation on perception of risk and safety, 
Kozak et al. (2007), Money and Crotts (2003) and Reisinger and Mavondo (2006a) agree that national culture has a significant influence on travel risk and safety perception.

Also, significant differences in risk perception have been found between American and ChineseMalaysian students when choosing Australia as a holiday destination (Summers \& McColl-Kennedy, 1998), between Cypriot and British students (Mitchell \& Vassos, 1997), and among tourists from various national cultures travelling to Israel (Fuchs \& Reichel, 2004). Nevertheless, it is worthy to note that the existing literature examining the influence of national culture on risk perception is conducted in the tourism context, none of them is conducted in the context of cruise ships. Within the cruise context, Palau-Saumell et al. (2015) reveals the significant effect of national culture on the cruising intentions of American and Spanish passengers. However, Palau-Saumell et al.'s (2015) study has touched a small tip of the iceberg 'national culture', showing limited knowledge of national culture's influence on risk perception of cruise passengers. In consideration of cruising's rapid global expansion, it is noteworthy for researchers to investigate the role of national culture as an influencer of cruiser risk perception:

P2: Perceptions of cruise-related risks are influenced by national culture.

\subsubsection{Gender}

Gender appears to be another key socio-demographic variable that explains differences in tourist's risk perception since women are found to be more susceptible to anxiety than men (Howell et al., 2001), more risk-adverse, more willing to express fear and more vulnerable to risk than men (Lepp \& Gibson, 2003; Lerner et al., 2003). Particularly, Reisinger and Crotts (2009) argue that travelling internationally is perceived to involve higher risk among women which results in more anxiety, insecure feelings, and less international travel intention than men regardless of their cultural background (Reisinger \& Crotts, 2009). Carr (2001) and Mitchell and Vassos (1997) suggest that risk tolerance of travellers differs among different genders. Also, significant gender differences in risktaking behaviour have been explored in Mattila et al.'s (2001) study even though Sönmez and Graefe's (1998a) findings did not support the influence of gender on risk perception.

However, Staats et al. (2006) did not support the claim that women express more fear or concern than men. It is argued that the different degree in expressing fear between men and women is consistent with social roles or expected gender norms (Lepp \& Gibson, 2003; Staats et al., 2006). Therefore, gender difference in risk perception and anxiety may derive from women's willingness to admit fear, which is less socially accepted for men in some cultures (Staats et al., 2006). Correspondingly, gender 
difference is believed to be contextual (Henderson, 1996), and dependent on cultural expectations and cultural norm constituting masculine and feminine behaviour (Culp, 1998; Putrevu, 2001). As a result, it is possible that behaviour differences between men and women reflect their culture values and traditions which differentiate the roles and rights of men and women (Reisinger \& Crotts, 2009). Thus, while there is a substantial absence in investigating gender factor in the cruising context, it is also important to determine the influence of gender in the combination with national culture factor on perception of travel risk:

P3: Perceptions of cruise-related risks are influenced by gender.

\subsubsection{Age}

Research suggests that the age of tourists has an important impact on their perception of travel risk and safety. In particular, Gibson and Yiannakis (2002) found that the degree of risk tolerance in tourism decreases with age; however, Sönmez and Graefe (1998b) did not find age as an important influencer of individual's risk perception. Also, Reisinger and Mavondo's (2006b) findings support that in contrast of gender, age controls only a few variables in some risk perceptions, anxiety, safety perception and intention to travel. Carr (2001) highlights the importance of understanding risk perception among young people. The author explains young tourists tend to possess motivations and personality traits that are different from the general population, thus, leading to difference in terms of perception of danger and safety, and group composition (Carr, 2001). Again, the overarching effect of national culture on differences in perception of travel risk, safety and anxiety is emphasised (Carr, 2001; Reisinger \& Mavondo, 2006b). This emphasis supports Pizam and Jeong's (1996) remark that "nationality is only one variable that should be considered in predicting variation in tourist behaviour and should never be used as a sole explanatory variable" (p. 285). Giving the increasing number of young passengers travelling on cruise ships, it is important to understand how tourists' age has impact on their perception of risk on cruise ships:

P4: Perceptions of cruise-related risks are influenced by age.

\subsubsection{Personality traits}

Literature shows that risk perception varies according to individual personality (Fuchs \& Reichel, 2004; Reisinger \& Mavondo, 2005, 2006b; Roehl \& Fesenmaier, 1992) and serves as an important factor in understanding the risk-acceptance level and risk perception in tourism (Roehl \& Fesenmaier, 1992; Sönmez \& Graefe, 1998a). Indeed, Reisinger and Mavondo (2005) discuss personality in terms of passive and active dimension where passive personality usually associates with low-level activities that generate peaceful, tranquil, enjoyable and secure feelings, while active personality induces 
excitement, stress, and even fear. It is insisted that individuals who are confident, extroverted, and adventurous have higher tolerance to the perceived risk and participate in more risky activities (Lepp \& Gibson, 2003; Plog, 2002; Reisinger \& Mavondo, 2005). On the other hand, risk avoiders may be more sensitive to risk and seek more safety and security when choosing a tourism product (Reisinger \& Mavondo, 2006b) while novelty and excitement seekers who are motivated by challenge and physical risks are more inclined to engage in risky and stressful products, thus obtain higher tolerance to some risk types (Berdychevsky \& Gibson, 2015; Lepp \& Gibson, 2003; Pizam et al., 2004; Sharifpour et al., 2013). Research indicates a significant relationship between sensational seeking and risk perception since the level of perceived risk is higher among low sensation seekers and lower among high sensation seekers (Lepp \& Gibson, 2008; Zuckerman, 1979). Furthermore, Pizam et al. (2004) emphasise the possibility that sensational-seeking, even though mostly demonstrated through personality or motivation, is significantly influenced by individual's nationality, meaning that national culture also has moderating role on the relationship between personality attributes and risk perception:

P5: Perceptions of cruise-related risks are influenced by personality traits.

\subsubsection{Motivation to travel}

In terms of travel motivation, Roehl and Fesenmaier (1992) categorised travellers into three groups with different travel risk perceptions based on their characteristics: Risk Neutral group, Functional Risk group, and Place Risk group. In particular, Risk Neutral group views their travel activities as relatively safe which induces the most risky behaviour in the three groups; they are likely to visit the destinations which are not previously visited and motivated by the benefit of experiencing adventure and excitement (Roehl \& Fesenmaier, 1992). In contrast, Place Risk group has had considerable experiences with their visited destinations and the main purpose of choosing those is oriented toward visiting relatives and friends, meaning that a trip to unvisited places is considered as very unlikely and risky to this group (Roehl \& Fesenmaier, 1992). The Functional Risk group involves the presence of young children which motivates strategy-taking to overcome some risks imposed by young children (Roehl \& Fesenmaier, 1992). The differences in motivations of these groups appear to be the determined factor influencing the perception of risk imposed by travel. Broadly speaking, it appears that personality and motivation impacts on risk perception is missing in the literature of cruising, while venturesome, novelty, and sensational-seeking are becoming key attributes of cruise passengers, especially of young cruisers, thus further research is required in this field to understand thoroughly these driven factors of risk perception among young travellers on cruise ships:

P6: Perceptions of cruise-related risks are influenced by motivation to travel. 


\subsubsection{Past travel experiences}

Past travel experience has been found to influence tourists' travel intentions (Sönmez \& Graefe, 1998a; Henthorne et al., 2013). In particular, personal experiences with travel in a particular product or destination can affect risk safety perceptions, which impact on whether the person can confirm or eliminate the choice, thus influence the decision of travelling to, or avoiding that product or destination (Sönmez \& Graefe, 1998a). More specifically, in cruising context, Henthorne et al. (2013) conduct a study to examine factors influencing risk perception on in-land shopping during a cruise trip. The results suggest that first time visitors express higher level of anxiety, discomfort and less secure feeling with the surrounding setting than the repeated, which in turn inhibits purchase behaviour. Hung and Petrick (2010) also found significant differences between perceived constraints of first-time cruisers and repeated cruisers. Bowen et al. (2014) identify passengers' attitude towards cruise ship's safety and security, where more experienced cruise passengers tend to portray greater confidence in the cruise ship companies than do the first-time passengers. Likewise, Baker and Stockton's (2013) study of food safety perception on cruise ships suggests cruise passengers who are less familiar with cruise attributes or have limited knowledge of food choices on cruise ships perceive greater food safety hazard. Research implies that past experience acts as an important influencer on perception of risk and safety on cruise ships (Baker \& Stockton, 2013):

P7: Perceptions of cruise-related risks are influenced by past travel experiences.

Past literature in the tourism context has suggested a number of key factors influencing risk perception, which are considered to be applicable in risk perception in the cruising context. These include national culture, gender, age, personality, motivation to travel, and past travel experiences. Since little research has been completed with these factors in the cruising context, this poses a significant possibility to investigate their influences on perception of cruise-related risks. More specifically, national culture appears to have the overarching effect on other factors, meaning that different groups of gender, age, personality, and motivation to travel may perceive risk differently in different culture dimensions:

P8: National culture has the moderation effect on the relationship between perceptions of cruiserelated risks and gender, age, personality traits and motivation to travel.

\section{Identified knowledge gaps}

This review identifies a number of research gaps that have not received sufficient investigation regarding the cruising decision-making process, perception of cruise-related risks, and factors 
influencing risk perception on cruising context. Firstly, further research is required to develop a cumulative process that enhances the prospect of conceptualising an ultimate decision-making framework for cruise passengers. In regard to this matter, Petrick et al. (2007) have proposed an initial conceptualisation of the decision-making processes, even though it is not exhaustive, it is considered a critical foundation for future development of a cruising decision-making framework. Secondly, there is a limited number of studies which investigate risk perception and its impact on cruiser decisionmaking. Among them, some studies narrow their scopes by examining cruisers' perceptions of specific risks associated with cruise ships such as food safety (Baker \& Stockton, 2013), terrorist threats (Bowen et al., 2014), and cruise safety (Ahola et al., 2014). These studies have touched only the smallest tip of the iceberg where perception has been examined among a single risk, which lacks a holistic view of risk perception on cruise ships where there are many threats perceived and faced by passengers.

Lastly, an analysis of the existing literature shows significant research gaps in examining factors influencing risk perception on cruise ships, which have solely been investigated in the tourism context. Those factors previously examined in the tourism context such as national culture, gender, age, personality and motivation has proved to be applicable to the cruising context. Therefore, in consideration of cruising's rapid global expansion, it is noteworthy for researchers to investigate these influential factors of risk perception on cruise ships. In conjunction with the significance of investigating young people's risk perception, these research gaps lead to a number of research propositions (see Figure 3). Figure 3 is a proposed conceptual model that presents the relationships between a number of relevant concepts regarding risk perception in cruising context, numerous research gaps identified in the existing cruising literature, the potential to measure risk perception by measuring perception of different types of risks young people associated with cruise ships, and potential factors influencing cruise risk perception. 


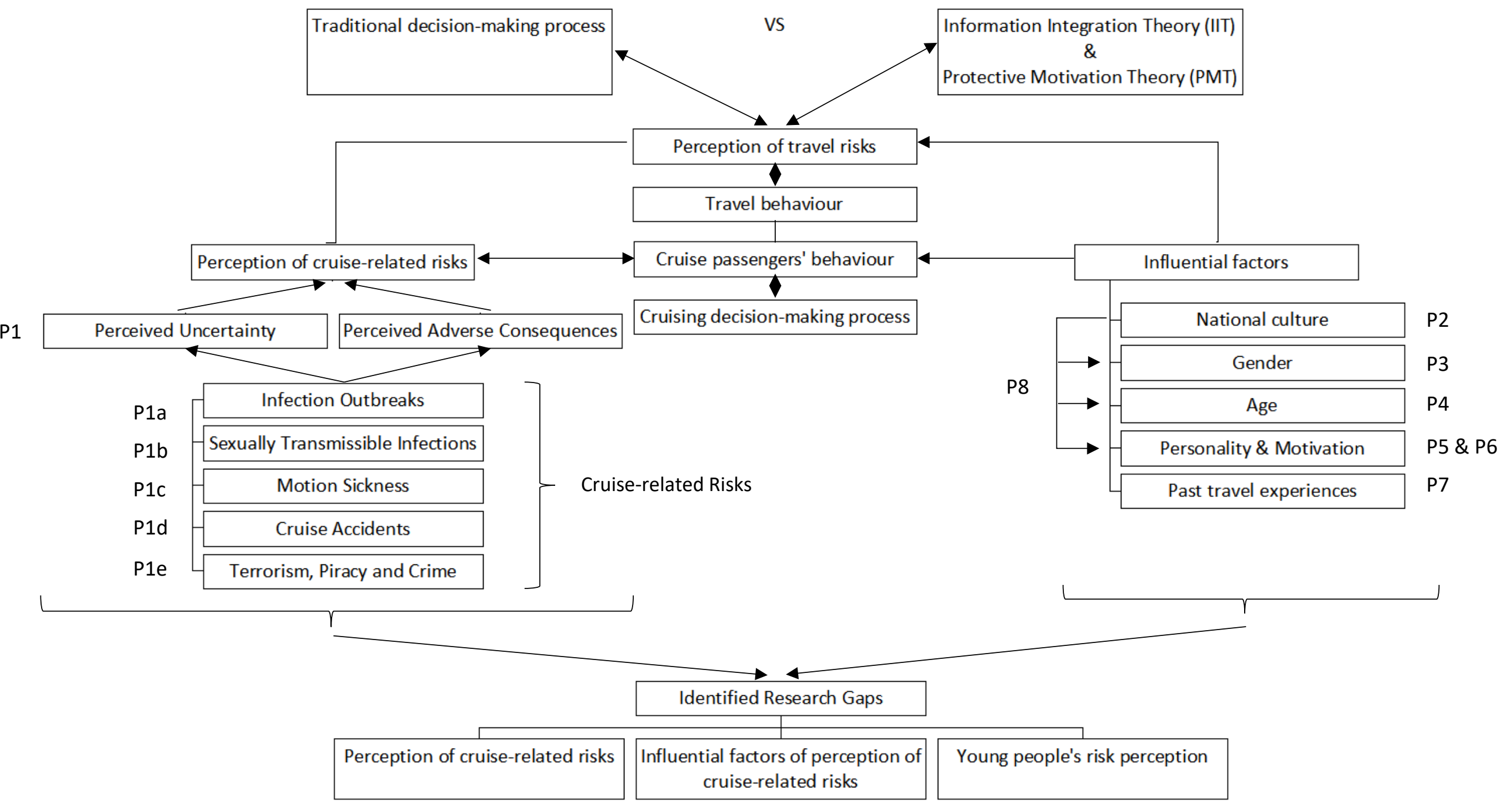

Figure 3. Conceptual model for perceptions of cruise-related risks. 


\section{Conclusion}

This discussion has shown that the scarce literature on cruising behaviour and risk perception on cruise ships results in key knowledge gaps in cruising context. Firstly, further research is required to conceptualise the decision-making framework for cruise passengers. Secondly, there is a need for deeper understanding about risk perception and its impact on cruiser decision-making because the absence of a holistic picture of perception of risk on cruise ships is evident. Thirdly, perception of cruise-related risks, especially among young people, is under-examined. Fourthly, despite numerous studies discussing the influential factors of risk perception in the tourism context, there is a need for further understanding on what factors influence risk perception in cruising context. Considering the significance of young people travelling by cruise ships, three research propositions have been suggested which would respond to the identified knowledge gaps.

This research is significant to both academics and practitioners. This research is valuable from an academic perspective because it offers a conceptual framework of risk perception in the cruising context that has not been previously generated. This framework is valued because of five reasons. Firstly, it conceptualises the fundamentals of risk perception including definition of risk and risk perception, the role of risk perception in travel behaviour, and theories underpinning risk perception. Secondly, it synthesises a number of risk perception measurements that have been utilised in previous studies and discusses the key relationship between the two perceived risk components: uncertainty and adverse consequences. Thirdly, the research poses significant directions for investigating the impacts of possible factors on risk perception. Fourthly, by identifying substantial knowledge gaps in the cruising context that have not received sufficient investigation, this research suggests future research implications regarding the cruising decision-making process, perception of cruise-related risks, and factors influencing risk perception. Fifthly, this research has a specific value by focusing on risk perception among young people, which has been neglected by previous literature. This study, however, has not discussed the technological risk as an emerging risk on cruise ships. Further research focusing more on technological issues on cruise ships and how they have impacts on passengers and ship safety is required.

For practitioners, this discussion is useful because it offers a deeper understanding of cruise passengers' behaviour and risk perception, which links directly to their experiences, satisfaction and retention. With the intense competition in the cruising industry which raises significant concerns for cruise operators, understanding the risk perceptions of young people allows cruise operators to respond more appropriately to market demand to improve their passengers' experiences; design 
effective marketing strategies that specifically target the cruising intentions and preferences of each group of customers; and, more importantly, enhance the effectiveness of risk management plans on cruise ships that correspond to the concerns of this increasingly important market segment. These benefits will help cruise operators attract new customers and maintain loyal customers, and create a competitive advantage for the businesses. 


\section{References}

Adler, P.A., \& Adler, P. (1998). Peer Power: Preadolescent Culture and Identity. New Brunswick, NJ: Rutgers University Press.

Ahola, M., Murto, P., Kujala, P., \& Pitkänen, J. (2014). Perceiving safety in passenger ships - user studies in an authentic environment. Safety Science, 70, 222-232.

Anderson, N. H. (1981). Foundations of Information Integration Theory. NY: Academic Press.

Anderson, N. H. (1982). Methods of Information Integration Theory. NY: Academic Press.

Baker, D. A., \& Stockton, S. (2013). Smooth sailing! Cruise passengers demographics and health perceptions while cruising the Eastern Caribbean. International Journal of Business and Social Science, 4(7), 8-17.

Bauer, R. A. (1960). Consumer behavior as risk taking. In S. Robert (Ed.), Dynamic Marketing for a Changing world (pp. 389-398). Hancock, Chicago, IL: American Marketing Association.

Bell, T. R., Kornylo Duong, K., Finelli, L., \& Slaten, D. D. (2014). Influenza surveillance on cruise ships. American Journal of Preventive Medicine, 46(3), 327-329.

Berdychevsky, L., \& Gibson, H. (2015). Women's sexual sensation seeking and risk taking in leisure travel. Journal of Leisure Research, 47(5), 621-646.

Bledsoe, G. H., Brill, J. D., Zak, D., \& Li, G. (2007). Injury and illness aboard an Antarctic cruise ship. Wilderness \& Environmental Medicine, 18(1), 36-40.

Bowen, C., Fidgeon, P., \& Page, S. (2014). Maritime tourism and terrorism: Customer perceptions of the potential terrorist threat to cruise shipping. Current Issues in Tourism, 17(7), 610-639.

Carr, N. (2001). An exploratory study of gendered differences in young tourists perception of danger within London. Tourism Management, 22(5), 565-570.

Chaudhuri, A. (2000). A macro analysis of the relationship of product involvement and information search: The role of risk. Journal of Marketing Theory and Practice, 8(1), 1-15.

Crilly, N., Moultrie, J., \& Clarkson, P. J. (2004). Seeing things: Consumer response to the visual domain in product design. Design Studies, 25(6), 547-577.

Crompton, J. (1992). Structure of vacation destination choice sets. Annals of Tourism Research, 19(3), 420-434.

Crotts, J. C. (1996). Theoretical perspectives on tourist criminal victimization. Journal of Tourism Studies, 7(1), 2-9.

Cruise Lines International Association (CLIA). (2016). 2016 Year in Review. Retrieved from https://www.cruising.org/docs/default-source/annualreports/clia_yearinreview_infog_2016_5-22.pdf?sfvrsn=2 
Cruise Lines International Association (CLIA). (2017). Cruise Travel Report January 2017. Retrieved from https://www.cruising.org/docs/defaultsource/research/clia_cruisetravelreport_2017.pdf?sfvrsn=8

Culp, R. H. (1998). Adolescent girls and outdoor recreation: A case study examining constraints and effective programming. Journal of Leisure Research, 30(3), 356-379.

Cunningham, S. (1967). The major dimensions of perceived risk. In D. F. Cox (Ed.), Risk taking and information handling in consumer behavior (pp. 82-108). Boston, MA: Harvard University Press.

Dowling, G. R. (1986). Perceived risk: The concept and its measurement. Psychology and Marketing, 3(3), 193-210.

Dowling, G. R., \& Staelin, R. (1994). A model of perceived risk and intended risk-handling activity. Journal of Consumer Research, 21(1), 119-134.

Dowling, R. K. (2006). Cruise ship tourism. Cambridge, MA: CABI Pub.

Fridgen, J. D. (1996). Dimensions of Tourism. East Lansing, MI: Educational Institute of the AHMA.

Fuchs, G., \& Reichel, A. (2004). Cultural differences in tourist destination risk perception: An exploratory study. Tourism-An International Interdisciplinary Journal, 52(1), 21-37.

Gibson, H., \& Yiannakis, A. (2002). Tourist roles: Needs and the lifecourse. Annals of Tourism Research, 29(2), 358-383.

Haddock, C. (1993). Managing risks in outdoor activities. Wellington, New Zealand: New Zealand Mountain Safety Council.

Hall, E. (1976). Beyond culture. NY: Doubleday, Anchor.

Henderson, K. A. (1996). One size doesn't fit all: the meaning of women's leisure. Journal of Leisure Research, 28(3), 139-154.

Henthorne, T. L., George, B. P., \& Smith, W. C. (2013). Risk perception and buying behavior: An examination of some relationships in the context of cruise tourism in Jamaica. International Journal of Hospitality and Tourism Administration, 14(1), 66-86.

Hofstede, G. (1980). Culture's consequences: International differences in work-related values. Beverly Hills, CA: Sage.

Hofstede, G., \& Bond, M. H. (1988). The Confucius connection: From cultural roots to economic growth. Organizational Dynamics, 16(4), 5-21.

Howell, H., Brawman-Mintzer, O., Monnier, O., \& Yonkers, K. (2001). Generalized anxiety disorder in women. Psychiatric Clinics of North America, 24, 165-178.

Hung, K., \& Petrick, J. F. (2010). Developing a measurement scale for constraints to cruising. Annals of Tourism Research, 37(1), 206-228. 
Hur, Y., \& Adler, H. (2013). An exploratory study of the propensity for South Koreans to take cruises: Investigating Koreans' perceptions of cruise ship travel. International Journal of Tourism Research, 15(2), 171-183.

ISO 31000. (2009). Risk management - Principles and guidelines. Retrieved from http://www.iso.org

Kak, V. (2007). Infections in confined spaces: Cruise ships, military barracks, and college dormitories. Infectious Disease Clinics of North America, 21(3), 773-784.

Kogan, N., \& Wallach, M. (1964). Risk taking. NY: Holt, Rinehart and Winston.

Kozak, M., Crotts, J. C., \& Law, R. (2007). The impact of the perception of risk on international travellers. International Journal of Tourism Research, 9(4), 233-242.

Krosnick, J. A. (2001). Americans' Perceptions of the Health Risks of Cigarette Smoking: A New Opportunity for Public Education (Faculty working paper, Ohio State University, Columbus, USA).

Lepp, A., \& Gibson, H. (2003). Tourist roles, perceived risk and international tourism. Annals of Tourism Research, 30(3), 606-624.

Lepp, A., \& Gibson, H. (2008). Sensation seeking and tourism: Tourist role, perception of risk and destination choice. Tourism Management, 29(4), 740-750.

Lerner, J. S., Gonzalez, R. M., Small, D. A., \& Fischhoff, B. (2003). Effects of fear and anger on perceived risks of terrorism: A national field experiment. Psychological Science, 14(2), 144150.

Maser, B., \& Weiermair, K. (1998). Travel decision-making: From the vantage point of perceived risk and information preferences. Journal of Travel \& Tourism Marketing, 7(4), 107-121.

Mattila, A., Apostolopoulos, Y., Sonmez, S., Yu, L., \& Sasidharan, V. (2001). The impact of gender and religion on college students' spring break behavior. Journal of Travel Research, 40(2), 193-200.

Mitchell, V., Davies, F., Moutinho, L., \& Vassos, V. (1999). Using neural networks to understand service risk in the holiday product. Journal of Business Research, 46(2), 167-180.

Mitchell, V., \& Vassos, V. (1997). Perceived risk and risk reduction in holiday purchases: A crosscultural and gender analysis. Journal of Euro - Marketing, 6(3), 47-79.

Money, R. B., \& Crotts, J. C. (2003). The effect of uncertainty avoidance on information search, planning, and purchases of international travel vacations. Tourism Management, 24(2), 191202.

Neri, A. J., Cramer, E. H., Vaughan, G. H., Vinjé, J., \& Mainzer, H. M. (2008). Passenger behaviors during Norovirus outbreaks on cruise ships. Journal of Travel Medicine, 15(3), 172-176.

Ni, H., Chen, N., \& Chen, A. (2010). Some extensions on risk matrix approach. Safety Science, 48(10), 1269-1278. doi:10.1016/j.ssci.2010.04.005 
Palau-Saumell, R., Forgas-Coll, S., \& Sánchez-García, J. (2015). The moderating effects of the nationality on the behavioral intentions of passengers on a Mediterranean holiday cruise. In Academy of Marketing Conference - The Magic in Marketing held 7-9 July 2015 at University of Limerick (pp. 1-9).

Panko, T. R., George, B. P., \& Henthorne, T. L. (2009). Personal safety and security on cruise ships: A study of crimes on board. Journal of Hospitality Application \& Research, 4(2), 31-44

Pavlic, I. (2013). Cruise tourism demand forecasting - the case of Dubrovnik. Tourism and Hospitality Management, 19(1), 125-142.

Petrick, J. F., Li, X., \& Park, S. (2007). Cruise passengers' decision-making processes. Journal of Travel \& Tourism Marketing, 23(1), 1-14.

Pizam, A., \& Jeong, G-H. (1996). Cross-cultural tourist behavior: Perceptions of Korean tour-guides. Tourism Management, 17(4), 277-286.

Pizam, A., Jeong, G., Reichel, A., van Boemmel, H., Lusson, J. M., Steynberg, L., \& Montmany, N. (2004). The relationship between risk-taking, sensation-seeking, and the tourist behavior of young adults: A cross-cultural study. Journal of Travel Research, 42(3), 251-260.

Pizam, A., \& Reichel, A. (1996). The effect of nationality on tourist behavior. Journal of Hospitality \& Leisure Marketing, 4(1), 23-49.

Pizam, A., \& Sussmann, S. (1995). Does nationality affect tourist behavior? Annals of Tourism Research, 22(4), 901-917.

Plog, S. C. (2002). The power of psychographics and the concept of venturesomeness. Journal of Travel Research, 40(3), 244-251.

Priest, S. (1990). The Adventure Experience Paradigm. In A. Miles \& S. Priest (Eds.), Adventure Recreation (pp. 157-62). State College, PA: Venture Publishing.

Pritchard, A., \& Morgan, N.J. (2006). Hotel Babylon? Exploring hotels as liminal sites of transition and transgression. Tourism Management, 27(5), 762-772.

Putrevu, S. (2001). Exploring the origins and information processing differences between men and women: Implications for advertising. Academy of Marketing Science Review, 2001(10), 1-14.

Reisinger, Y., \& Crotts, J. C. (2009). The influence of gender on travel risk perceptions, safety, and travel intentions. Tourism Analysis, 14(6), 793-807.

Reisinger, Y., \& Mavondo, F. (2005). Travel anxiety and intentions to travel internationally: Implications of travel risk perception. Journal of Travel Research, 43(3), 212-225.

Reisinger, Y., \& Mavondo, F. (2006a). Cultural consequences on traveler risk perception and safety. Tourism Analysis, 11(4), 265-284. 
Reisinger, Y., \& Mavondo, F. (2006b). Cultural differences in travel risk perception. Journal of Travel \& Tourism Marketing, 20(1), 13-31.

Richardson, S. L., \& Crompton, J. (1988). Vacation patterns of French and English Canadians. Annals of Tourism Research, 15(3), 430-435.

Roehl, W. S., \& Fesenmaier, D. R. (1992). Risk perceptions and pleasure travel: An exploratory analysis. Journal of Travel Research, 30(4), 17-26.

Rogers, R. W. (1975). A Protection Motivation Theory of Fear Appeals and Attitude Change. Journal of Psychology, 91(1), 93-114.

Rogers, R. W. (1983). Cognitive and Physiological Process in Fear Appeals and Attitude Change: A Revised Copy of Protection Motivation. In J. Cacioppo \& R. Petty (Eds.), Social Psychophysiology (pp. 153-74). NY: Guilford.

Schmidt, F. L., \& Wilson, T. C. (1975). Expectancy value models of attitude measurement: A measurement problem. Journal of Marketing Research, 12(3), 366-368.

Seddighi, H. R., Nuttall, M. W., \& Theocharous, A. L. (2001). Does cultural background of tourists influence the destination choice? An empirical study with special references to political instability. Tourism Management, 22(2), 181-191.

Selänniemi, T. (2003). On holiday in the liminoid playground: Place, time, and self in tourism. In T. G. Bauer \& B. McKercher (Eds.), Sex and tourism: Journeys of romance, love, and lust (pp. 19-31). NY: The Haworth Hospitality Press.

Sharifpour, M., Walters, G., \& Ritchie, B. W. (2013). The mediating role of sensation seeking on the relationship between risk perceptions and travel behavior. Tourism Analysis, 18(5), 543-557.

Slovic, P. (1987). Perception of risk. Science, 236(4799), 280-285.

Slovic, P., Fischhoff, B., \& Lichtenstein, S. (1982). Why study risk perception? Risk Analysis, 2(2), 8393.

Sönmez, S. F., \& Graefe, A. R. (1998a). Determining future travel behaviour from past travel experience and perceptions of risk and safety. Journal of Travel Research, 37(2), 171-177.

Sönmez, S. F., \& Graefe, A. R. (1998b). Influence of terrorism risk on foreign tourism decisions. Annals of Tourism Research, 25(1), 112-144.

Staats, S., Panek, P., \& Cosmar, D. (2006). Predicting travel attitudes among university faculty after 9/11. The Journal of Psychology, 140(2), 121-132.

Stone, R., \& Winter, F. (1985). Risk in buyer behavior in contexts: A clarification (Faculty working paper 1216 EWP 860505). College of Commerce and Business Administration, University of Illinois, IL. 
Summers, J., \& McColl-Kennedy, J. (1998). Australia as a holiday destination: Young Americans' vs. Chinese Malaysians' decision-making. Journal of Hospitality and Leisure Marketing, 5(4), 3355.

Ventikos, N. P. (2013). Exploring fire incidents/accidents onboard cruise and passenger ships. Journal of Economics and Business, 63(3-4), 146-157.

Yüksel, F., \& Yüksel, A. (2007). Shopping risk perceptions: Effects on tourists' emotions, satisfaction and expressed loyalty intentions. Tourism Management, 28(3), 703-713.

Zuckerman, M. (1979). Sensation Seeking: Beyond the Optimal Level of Arousal. Hillsdale, NJ: Lawrence Erlbaum. 